\title{
Ginsenoside Rb1 prevents interleukin-1 beta induced inflammation and apoptosis in human articular chondrocytes
}

\author{
Wendan Cheng • Dongying Wu • Qiang Zuo • \\ Zhen Wang • Weimin Fan
}

Received: 15 May 2013 / Accepted: 17 June 2013 / Published online: 9 July 2013

(C) The Author(s) 2013. This article is published with open access at Springerlink.com

\begin{abstract}
Purpose Osteoarthritis (OA) is an age-related joint disease that is characterised by the degeneration of articular chondrocytes. Ginsenosides, the most important pharmacological ingredients of ginseng, have been proven to provide effective therapy for neurodegenerative diseases and can inhibit cell apoptosis. We investigated whether ginsenoside Rb1 can modulate inflammation and apoptosis in human chondrocytes.

Methods Chondrocytes were isolated from OA patients undergoing total knee replacement surgery. Apoptosis was assessed by TUNEL (terminal deoxyribonucleotide transferasemediated dUTP nick end-labelling)-positive staining. Levels of PGE2 and $\mathrm{NO}^{2}$ - were detected by ELISA. Gene expression levels were measured for type II collagen (Col2A1), aggrecan, MMP13, COX-2, iNOS, caspase-3, and PARP.

Results The results showed that TUNEL-positive staining chondrocytes were decreased by Rb1 compared with IL$1 \beta$. Both 10 or $100 \mu \mathrm{g} / \mathrm{ml} \mathrm{Rb1}$ inhibited the effect of IL$1 \beta$ on chondrocytes by decreasing levels of PGE2, $\mathrm{NO}^{2}-$, $M M P-13, C O X-2, i N O S$, caspase-3 and PARP and increasing
\end{abstract}

Wendan Cheng and Dongying Wu are co-first authors.

W. Cheng $\cdot$ Q. Zuo $\cdot$ W. Fan $(\bowtie)$

Department of Orthopedics, The First Affiliated Hospital

of Nanjing Medical University, 300 Guang Zhou Road,

Nanjing 210000, China

e-mail: docweiminfan@126.com

W. Cheng

Lu'an People's Hospital Affiliated to Anhui Medical University, Lu'an 237000, China

D. $\mathrm{Wu}$

Department of Orthopedics, The Affiliated Hospital of Xuzhou

Medical College, Xuzhou 221006, China

Z. Wang

Department of Orthopedics, The People's Hospital of Luhe, Luhe 211500, China aggrecan and Col2A1 gene expression levels, to block IL$1 \beta$-induced cell inflammation and apoptosis.

Conclusions The results suggest that $\mathrm{Rb} 1$ possesses potential anti-inflammatory and anti-apoptotic properties in human chondrocytes, possibly by binding to oestrogen receptors to exert its pharmacological effects.

\section{Introduction}

Osteoarthritis (OA) is an age-related joint disease that is characterised by the degeneration of articular chondrocytes [1]. Chondrocytes are only one cell type which are responsible for the maintenance of the extracellular matrix (ECM). Interleukin-1 beta (IL-1 $\beta$ ) causes inflammation of articular cartilage, stimulates the production of matrix metalloproteinases (MMPs), cyclo-oxygenase-2 (COX-2) and prostaglandin E2 (PGE2), and is therefore a target for therapeutic strategies $[2,3]$. These inflammatory cytokines can further inhibit the synthesis of the main constituents of the ECM, type II collagen (Col2A1) and aggrecan (ACAN), and can disrupt the balance of metabolism in articular cartilage. Apoptosis is thought to have a pivotal role in human and animal OA [4]. It has been reported that apoptosis of chondrocytes can be induced by different agents, such as caspase-3 and inducible nitric oxide synthase (iNOS) [5, 6]. During apoptotic cell death caspases activate the cleavage of the DNA repair enzyme poly(ADPribose) polymerase (PARP) in chondrocytes.

Ginsenosides, the most important pharmacological ingredients of ginseng, have been proven to provide effective therapy for neurodegenerative diseases and can inhibit cell apoptosis. To date, more than 40 different ginsenosides have been identified and isolated from the root of ginseng [7]. Ginsenosides are generally divided into two groups, panaxadiols and panaxatriols, based on the chemical structure [8]. Panaxadiols include compounds called ginsenoside Rb1 (Rb1), which is the most abundant among more than 40 ginsenosides. A previous 
study has shown that $\mathrm{Rb} 1$ can exert a suppressive effect on local inflammation in rats with cerebral ischemia [9]. Furthermore, Rb1 protects $\mathrm{PC} 12$ cells from apoptosis through stimulation of the oestrogen receptor [10]. However, no data yet has been reported concerning the effect of $\mathrm{Rb} 1$ on apoptosis and inflammation in chondrocytes or its therapeutic role in OA.

In this study we investigated whether $\mathrm{Rb} 1$ is able to inhibit apoptosis and inflammatory responses in OA by establishing an in vitro model in human chondrocytes.

\section{Materials and methods}

\section{Materials}

$\mathrm{Rb} 1$ was purchased from the National Institutes for Food and Drug Control (Beijing, China). Recombinant human IL-1 $\beta$ was provided by R\&D Systems (St. Paulo, MN, USA). High glucose diluted Dulbecco's modified Eagle's medium (DMEM), foetal bovine serum (FBS), 6-dianidino-2-phenylindole dihydrochloride (DAPI) and penicillin/streptomycin were obtained from Gibco (NY, USA). In Situ Cell Apoptosis Detection kits were purchased from Roche Diagnostics (East Sussex, UK).

\section{Cell culture}

All experiments were approved by the Ethical Committee of Nanjing Medical University. Articular cartilage samples were obtained from OA patients undergoing total knee replacement surgery. All patients were diagnosed using the criteria of the American College of Rheumatology. Harvested cartilage was minced into small pieces and incubated in a trypsin-containing solution for two hours at $37^{\circ} \mathrm{C}$. The pieces were then washed with phosphatebuffered saline (PBS) and incubated at $37^{\circ} \mathrm{C}$ overnight in $0.2 \%$ collagenase. After digestion, the chondrocytes were collected and cultured in DMEM/F12 medium containing $10 \%$ FBS and $100 \mathrm{U} / \mathrm{ml}$ of penicillin-streptomycin at $37{ }^{\circ} \mathrm{C}$ in a humidified $5 \% \mathrm{CO}_{2}$ atmosphere. Cells were used at passage 0 or 1 to avoid dedifferentiation.

\section{Experimental design}

First-generation human chondrocytes were cultured in DMEM medium without serum and with $2 \%$ serumfree bovine serum albumin (BSA) for 24 hours after washing three times with PBS to prevent the influence of other cytokines. Cells were treated with $10 \mathrm{ng} / \mathrm{ml} \mathrm{IL-}$ $1 \beta$ and $\mathrm{Rb} 1$ at 1,10 and $100 \mu \mathrm{g} / \mathrm{ml}$. A positive control group consisted of cells treated with $10 \mathrm{ng} / \mathrm{ml} \mathrm{IL-1 \beta}$ alone. A negative control group was untreated except for a change in the medium. Cells were harvested after incubation for 24 hours.

\section{Cell apoptosis}

According to the manufacturer's instructions, terminal deoxynucleotidyl transferase-mediated deoxyuridine triphosphate-biotin nick end-labelling (TUNEL) was performed to detect cell apoptosis. Images were randomly selected from two sections of each specimen and the stained cells were counted under 400 magnification. Chondrocytes were stained with DAPI at $37{ }^{\circ} \mathrm{C}$ for 30 minutes Apoptotic chondrocytes were recognised with dual TUNEL and DAPI staining. For each group in experiments, three images were randomly selected using an inverted fluorescence microscope.

\section{Quantification of nitrite $\left(\mathrm{NO}_{2}^{-}\right)$and PGE2 concentrations}

ELISA kits were used to measure $\mathrm{NO}_{2}^{-}$and PGE2 levels according to the manufacturer's protocol. $\mathrm{NO}_{2}{ }^{-}$ concentrations were determined using the respective standard curves and normalised against the control concentration.

RNA extraction and quantitative real-time polymerase chain reaction $(\mathrm{PCR})$

Gene expression levels of Col2A1, ACAN, MMP-13, COX-2, iNOS, caspase-3, PARP and $\beta$-actin of human chondrocytes induced by IL-1 $\beta$ were determined using real-time PCR. TRIzol and chloroform reagents were used to extract total RNA according to the manufacturer's instructions. RNA concentrations were measured using a spectrophotometer; samples with values of 1.7-2.0 were used. Complimentary DNA (cDNA) was synthesised from RNA using reverse transcriptase and a PrimeScript RT reagent kit (Fermentas, Lithuania). Real-time PCR was carried out by combining $2 \mu$ of cDNA with reagents from the SYBR Premix Ex Taq II to give a total volume of $20 \mu \mathrm{l}$. The generation of specific PCR products was confirmed by melting-curve analysis; mRNA encoding $\beta$ actin served as an internal control. Gene expression data for the proteins of interest were standardised against $\beta$-actin. The primers (TaKaRa, Japan) used are shown in Table 1.

Analysis

Results are expressed as mean \pm standard deviation (SD). All analyses were performed using SPSS version 16.0 software (SPSS Inc., Chicago, IL, USA). For multiple comparisons, one-way analysis of variance was used depending on the experiment design. A $p$ value of $<0.05$ was considered statistically significant. 
Table 1 Sequences of primers for the quantitative RT-PCR experiments

\begin{tabular}{|c|c|c|c|}
\hline Gene & Sense & Sequence $5^{\prime} \rightarrow 3^{\prime}$ & $\operatorname{Size}(\mathrm{pb})$ \\
\hline$\beta$-actin & $\begin{array}{l}\mathrm{F} \\
\mathrm{R}\end{array}$ & $\begin{array}{l}\text { GCAGAAGGAGATCACTGCCCT } \\
\text { GCTGATCCACATCTGCTGGAA }\end{array}$ & 136 \\
\hline Caspase-3 & $\begin{array}{l}\mathrm{F} \\
\mathrm{R}\end{array}$ & $\begin{array}{l}\text { CATGGAAGCGAATCAATGGACT } \\
\text { CTGTACCAGACCGAGATGTCA }\end{array}$ & 139 \\
\hline iNOS & $\begin{array}{l}\mathrm{F} \\
\mathrm{R}\end{array}$ & $\begin{array}{l}\text { ACCAGTACGTTTGGCAATGG } \\
\text { TCAGCATGAAGAGCGATTTCT }\end{array}$ & 70 \\
\hline PARP & $\begin{array}{l}\mathrm{F} \\
\mathrm{R}\end{array}$ & $\begin{array}{l}\text { TCTTTGATGTGGAAAGTATGAAGAA } \\
\text { GGCATCTTCTGAAGGTCGAT }\end{array}$ & 64 \\
\hline MMP-13 & $\begin{array}{l}\mathrm{F} \\
\mathrm{R}\end{array}$ & $\begin{array}{l}\text { TCCTGATGTGGGTGAATACAATG } \\
\text { GCCATCGTGAAGTCTGGTAAAAT }\end{array}$ & 184 \\
\hline ACAN & $\begin{array}{l}\mathrm{F} \\
\mathrm{R}\end{array}$ & $\begin{array}{l}\text { GTGCCTATCAGGACAAGGTCT } \\
\text { GATGCCTTTCACCACGACTTC }\end{array}$ & 167 \\
\hline COX-2 & $\begin{array}{l}\mathrm{F} \\
\mathrm{R}\end{array}$ & $\begin{array}{l}\text { CTTACAATGCTGACTATGGCTAC } \\
\text { AAACTGATGCGTGAAGTGCTG }\end{array}$ & 242 \\
\hline Col2A1 & $\begin{array}{l}\mathrm{F} \\
\mathrm{R}\end{array}$ & $\begin{array}{l}\text { TTCAGCTATGGAGATGACAATC } \\
\text { AGAGTCCTAGAGTGACTGAG }\end{array}$ & 472 \\
\hline
\end{tabular}

\section{Results}

Effect of Rb1 on chondrocyte apoptosis

TUNEL staining confirmed the effect of Rb1 on chondrocyte apoptosis (Fig. 1). Percentage of TUNEL positive cells after 48 hours of IL- $1 \beta$ exposure was $37.30 \%$, which was higher than control $(p<0.05)$. When the chondrocytes were cocultured with $10 \mu \mathrm{g} / \mathrm{ml}$ of IL-1 $\beta$ and Rb1 the percentage of TUNEL positive cells $(20.33 \%)$ was lower than the IL-1 $\beta$ group $(p<0.05)$.

Effects of Rb1 on IL-1 $\beta$-induced Col2A1 and AGAN gene expression

Quantitative real-time PCR was used to analyse gene expression. Stimulation with IL-1 $\beta(10 \mathrm{ng} / \mathrm{ml})$ led to a 2.9-fold decrease of Col2A1 and $A C A N$ gene expression compared to the negative control $(p<0.05)$ (Fig. 2). They were increased 1.7and 2.3-fold $(p<0.05)$ after co-treatment with $10 \mu \mathrm{g} / \mathrm{ml} \mathrm{Rb1}$, and 2.4- and 2.0-fold $(p<0.05)$ after co-treatment with 100$\mu \mathrm{g} / \mathrm{ml} \mathrm{Rb} 1$. However, no effect was found with $1 \mu \mathrm{g} / \mathrm{ml} \mathrm{Rb} 1$ $(p>0.05)$. The effect of $\mathrm{Rb} 1$ was found to be dose-dependent.

Rb1 inhibited MMP-13 and COX-2 gene expression and IL-1 $\beta$-induced PGE2 production

IL-1 $\beta$ stimulation $(10 \mathrm{ng} / \mathrm{ml})$ for 24 hours led to a 27.2 -fold increase in $M M P-13$ gene expression compared to the negative control $(p<0.05)$ (Fig. 3). On addition of 10 or $100 \mu \mathrm{g} / \mathrm{ml}$ $\mathrm{Rb} 1, M M P-13$ gene expression decreased by 4.8 - or 4.4 -fold, respectively $(p<0.05)$. Stimulation with IL-1 $\beta(10 \mathrm{ng} / \mathrm{ml})$ led to a 19.8-fold increase in $C O X-2$ gene expression. After co-treatment with 10 or $100 \mu \mathrm{g} / \mathrm{ml} \mathrm{Rb1,COX-2}$ gene expression levels were reduced 3.0- or 2.5-fold $(p<0.05)$. However, no effect was found at $1 \mu \mathrm{g} / \mathrm{ml} \mathrm{Rb} 1$.

Levels of PGE2 in the supernatant were assessed using ELISA. As shown in Fig. 3, stimulation of human chondrocytes with IL-1 $\beta$ produced a two-fold increase in PGE2 compared with the control $(p<0.05)$. Interestingly, chondrocytes stimulated with IL-1 $\beta$ in the presence of 10 or $100 \mu \mathrm{g} / \mathrm{ml} \mathrm{Rb} 1$ led to 3 -fold decrease in PGE2 $(p<0.05)$.

Rb1 inhibited iNOS, caspase- 3 and PARP gene expression and IL- $1 \beta$-induced nitric oxide $(\mathrm{NO})$ production

Stimulation with IL-1 $\beta(10 \mathrm{ng} / \mathrm{ml})$ for 24 hours led to a 111.2-fold increase in $i N O S$ gene expression as well as a six-fold increase in NO production in the supernatant $(p<0.05)$ (Fig. 4). At a concentration of $1 \mu \mathrm{g} / \mathrm{ml}, \mathrm{Rb} 1$ slightly decreased the gene expression of $i N O S$ and production of NO $(p>0.05)$, whereas at a concentration of $10 \mu \mathrm{g} / \mathrm{ml}$ the gene expression of $i N O S$ and production of NO decreased by 6.5- and 2.6-fold, respectively $(p<0.05)$. Rb1 at a concentration of $100 \mu \mathrm{g} / \mathrm{ml}$ decreased the gene expression of $i N O S$ and production of NO 6.5- and 4.0-fold, respectively $(p<0.05)$. Stimulation with IL-1 $\beta(10 \mathrm{ng} / \mathrm{ml})$ led to a 5.4fold increase in caspase- 3 and a 3.0 -fold increase in PARP $(p<0.05)$ (Fig. 4). They were decreased 2.3- and 2.7-fold after co-treatment with $10 \mu \mathrm{g} / \mathrm{ml} \mathrm{Rb1}$ and 1.9- and 2.0-fold after co-treatment with $100 \mu \mathrm{g} / \mathrm{ml} \mathrm{Rb} 1(p<0.05)$. However, no effect was found at $1 \mu \mathrm{g} / \mathrm{ml} \mathrm{Rb} 1(p>0.05)$.

\section{Discussion}

Ginsenoside $\mathrm{Rb} 1$ is one of the richest subtypes in quantity among 30 ginsenosides, which exert multiple biological 
Fig. 1 Effect of Rb1 on

chondrocyte apoptosis. All data are mean $\pm \mathrm{SD} . \star \star p<0.05$ vs. the IL group. $\star p<0.05$ vs. the control

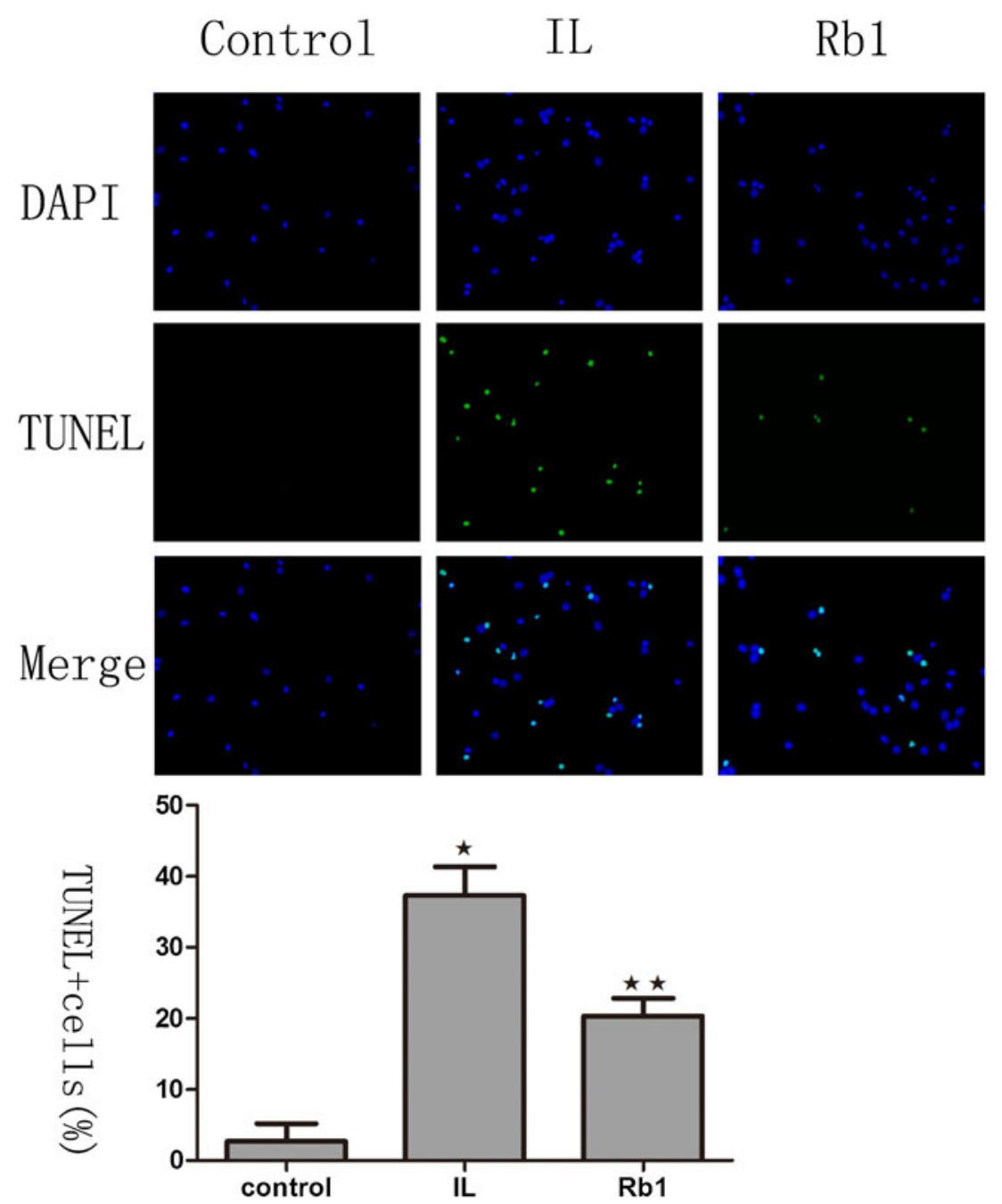

actions including anti-inflammatory, anti-apoptosis, and neuroprotective activities $[10,11]$. In this paper, our findings suggest that Rb1 can inhibit the production of inflammatory agents such as MMP-13, COX-2, PGE2, iNOS and NO, and decrease Col2A1 and ACAN degradation induced by IL- $1 \beta$ in human articular chondrocytes. Real-time PCR results showed that Rb1 inhibited the gene expression of the apoptotic biomarkers, caspase-3 and PARP, in chondrocytes.

IL-1 $\beta$ leads to the production and accumulation of high levels of pro-inflammatory cytokines in OA synovial cells and chondrocytes. These trigger the production of additional proinflammatory cytokines which induce genes encoding COX-2 and matrix-degrading enzymes such as MMPs. Furthermore,
Fig. 2 Effect of Rb1 on IL-1ßinduced Col2A1 and AGAN gene expression. The normalised gene expression levels are expressed as ratios of the copy number of the mRNA and that of $\beta$-actin cDNA. Data were obtained from three independent experiments and are presented as the mean \pm SD. $\star \star p<0.05$ vs. the control. $\star p<0.05$
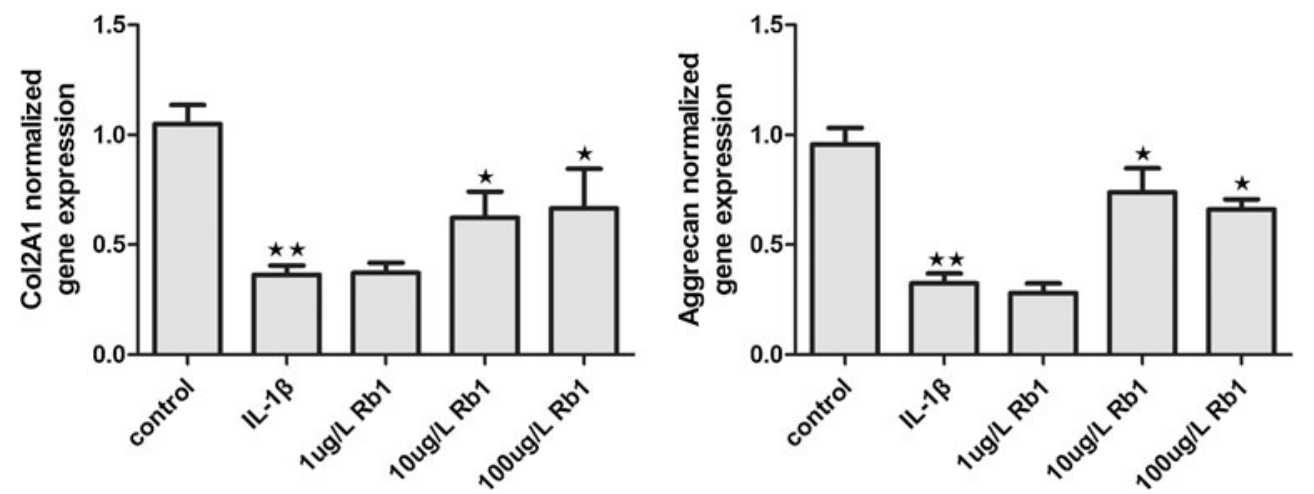
Fig. 3 Effect of Rb1 on IL-1 $\beta$ induced MMP-13 and COX-2 gene expression and IL- $1 \beta$ induced PGE2 production. The normalised gene expression levels are expressed as ratios of the copy number of the mRNA and that of $\beta$-actin cDNA. Data were obtained from three independent experiments and are presented as the mean $\pm \mathrm{SD}$. $\star \star p<0.05$ vs. the control. $\star p<0.05$ vs. the IL-1 $\beta$ group
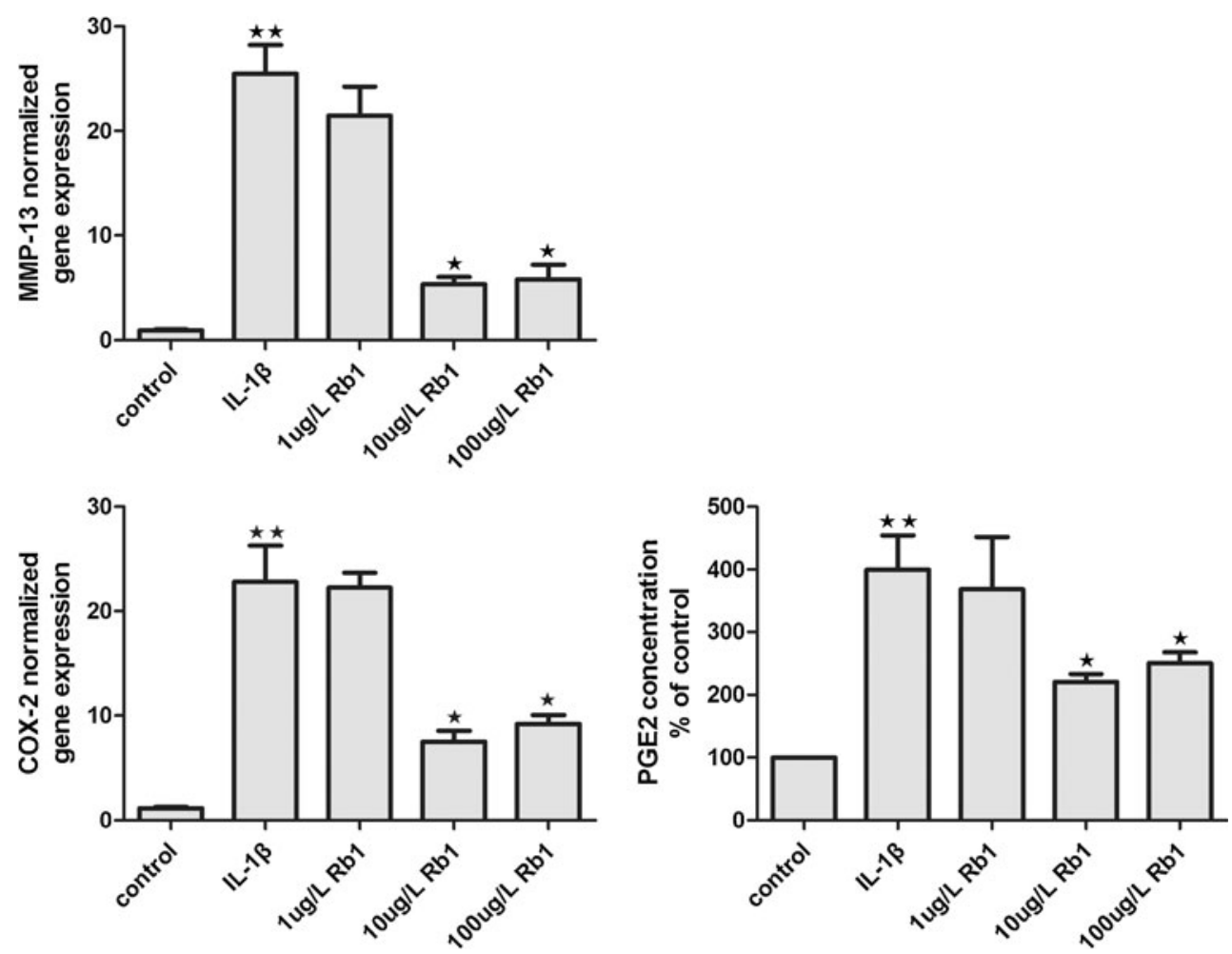

COX-2 converts arachidonic acid into PGE2, which together with COX-2, sensitise peripheral receptors and cause pain [12, 13]. In the present study, we found that elevated COX-2 and MMP-13 gene expression and PGE2 production in IL-1 $\beta$ - induced cells was suppressed by the addition of $\mathrm{Rb} 1$. This suggests that $\mathrm{Rb} 1$ may act as an anti-inflammatory similar to NSAIDs, which have been shown to ameliorate OA symptoms by inhibiting the expression of $C O X-2$ and PGE2 [14].
Fig. 4 Effect of Rb1 on IL-1 $\beta$ induced iNOS caspase-3 and PARP gene expression and IL$1 \beta$-induced NO production. The normalized gene expression levels are expressed as ratios of the copy number of the mRNA and that of $\beta$-actin cDNA.

Culture media were analysed for NO2- concentration. All data shown were the mean $\pm \mathrm{SD}$ of $\mathrm{NO} 2$ - concentration as a percentage of the control. $\star \star p<0.05$ vs. the control. $\star p<0.05$ vs. the IL-1 $\beta$
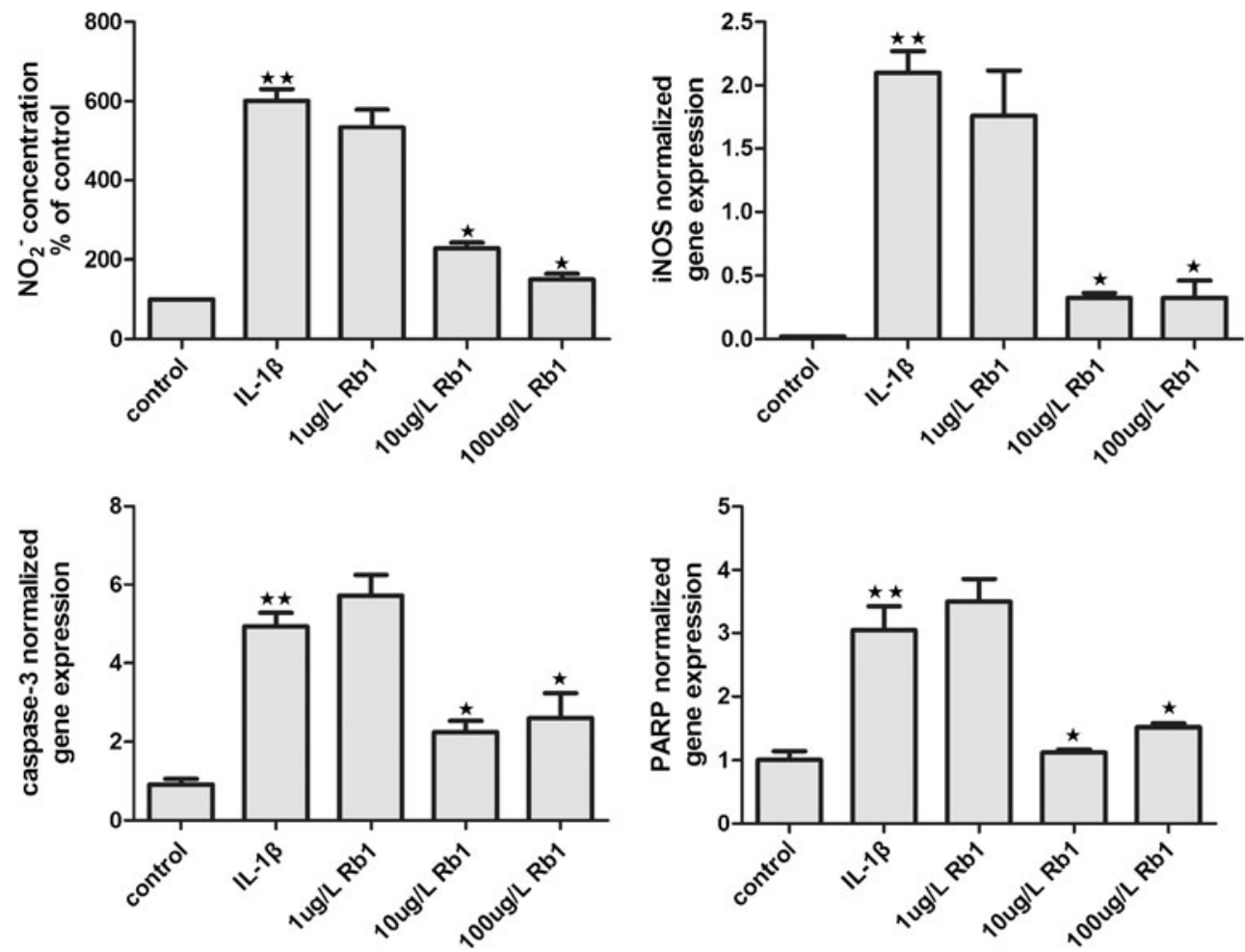
It is widely accepted that increased IL- $1 \beta$ levels can trigger apoptosis in chondrocytes, which leads to further degenerative changes in cartilage. Of the 12 caspases in mammals, caspase-3 is a crucial biomarker of apoptosis that also acts as an apoptotic executor [15]. PARP, a downstream target of caspase-3, is a nuclear enzyme normally involved in DNA repair, but extensive activation of PARP promotes cell death [16]. We found that levels of mRNAs encoding caspase-3 and PARP in human chondrocytes treated with IL-1 $\beta$ were upregulated, whereas co-treatment with $\mathrm{Rb} 1$ downregulated the expression levels of these genes in IL$1 \beta$-stimulated chondrocytes. Our findings indicate that $\mathrm{Rb} 1$ could inhibit chondrocyte apoptosis induced by IL-1 $\beta$.

Evidence has confirmed the existence of two oestrogen receptors (ERs) in the articular cartilage, indicating that the cartilage can respond to estrogen [17]. Oestrogen has a protective effect in OA [18]. Rb1 could exert an oestrogen-like effect by binding to ERs [19]. Hashimoto et al. found that ginsenoside $\mathrm{Rb} 1$ protects $\mathrm{PC} 12$ cells from caspase-3-dependent apoptosis through stimulation of oestrogen receptors [10]. We suggest that $\mathrm{Rb} 1$ acts in a similar way to oestrogen in treating OA.

In conclusion, our work shows that $\mathrm{Rb} 1$ possesses potential anti-inflammatory and anti-apoptotic properties in human chondrocytes, possibly through binding to ERs to exert pharmacological effects. These findings suggest that $\mathrm{Rb} 1$ may help protect against the degeneration of cartilage in patients with OA.

Conflict of interest The authors declare that they have no conflict of interest.

\section{Disclosures None.}

Open Access This article is distributed under the terms of the Creative Commons Attribution License which permits any use, distribution, and reproduction in any medium, provided the original author(s) and the source are credited.

\section{References}

1. Loeser RF (2009) Aging and osteoarthritis: the role of chondrocyte senescence and aging changes in the cartilage matrix. Osteoarthr Cartil 17:971-979. doi:10.1016/j.joca.2009.03.002

2. Dai SM, Shan ZZ, Nakamura H et al (2006) Catabolic stress induces features of chondrocyte senescence through overexpression of caveolin 1: possible involvement of caveolin 1-induced downregulation of articular chondrocytes in the pathogenesis of osteoarthritis. Arthritis Rheum 54:818-831
3. Yudoh K, Nguyen V, Nakamura H et al (2005) Potential involvement of oxidative stress in cartilage senescence and development of osteoarthritis: oxidative stress induces chondrocyte telomere instability and downregulation of chondrocyte function. Arthritis Res Ther 7:R380 R391

4. Aigner T, Kim HA (2002) Apoptosis and cellular vitality: issues in osteoarthritic cartilage degeneration. Arthritis Rheum 46:19861996

5. Rath PC, Aggarwal BB (1999) TNF-induced signaling in apoptosis. J Clin Immunol 19:350-364

6. Shakibaei M, Schulze-Tanzil G, Takada Y et al (2005) Redox regulation of apoptosis by members of the TNF superfamily. Antioxid Redox Signal 7:482-496

7. Cheng Y, Shen LH, Zhang JT (2005) Anti-amnestic and anti-aging effects of ginsenoside $\mathrm{Rg} 1$ and $\mathrm{Rb} 1$ and its mechanism of action. Acta Pharmacol Sin 26:143-149

8. Seo JY, Lee JH, Kim NW et al (2005) Effect of a fermented ginseng extract, BST204, on the expression of cyclooxygenase-2 in murine macrophages. Int Immunopharmacol 5:929-936

9. Zhu J, Jiang Y, Wu L et al (2012) Suppression of local inflammation contributes to the neuroprotective effect of ginsenoside $\mathrm{Rb} 1 \mathrm{in}$ rats with cerebral ischemia. Neuroscience 202:342-351. doi:10.1016/j. neuroscience

10. Hashimoto R, Yu J, Koizumi H et al (2012) Ginsenoside Rb1 prevents MPP(+)-induced apoptosis in PC12 cells by stimulating estrogen receptors with consequent activation of ERK1/2, Akt and inhibition of SAPK/JNK, p38 MAPK. Evid Based Complement Alternat Med 2012:693717

11. Radad K, Gille G, Moldzio R et al (2004) Ginsenosides Rb1 and Rg1 effects on mesencephalic dopaminergic cells stressed with glutamate. Brain Res 1021:41-53

12. Li X, Ellman M, Muddasani P et al (2009) Prostaglandin E2 and its cognate EP receptors control human adult articular cartilage homeostasis and are linked to the pathophysiology of osteoarthritis. Arthritis Rheum 60:513-523. doi:10.1002/art.24258

13. Knorth H, Dorfmuller P, Lebert R et al (2004) Participation of cyclooxygenase-1 in prostaglandin E2 release from synovitis tissue in primary osteoarthritis in vitro. Osteoarthr Cartil 12:658-666

14. Nakamura H, Shibakawa A, Tanaka M et al (2004) Effects of glucosamine hydrochloride on the production of prostaglandin E2, nitric oxide and metalloproteases by chondrocytes and synoviocytes in osteoarthritis. Clin Exp Rheumatol 22:293-299

15. Loeser RF, Erickson EA, Long DL (2008) Mitogen-activated protein kinases as therapeutic targets in osteoarthritis. Curr Opin Rheumatol 20:581-586. doi:10.1097/BOR.0b013e3283090463

16. Le DA, Wu Y, Huang $Z$ et al (2002) Caspase activation and neuroprotection in caspase-3- deficient mice after in vivo cerebral ischemia and in vitro oxygen glucose deprivation. Proc Natl Acad Sci USA 99:15188-15193

17. Richette P, Corvol M, Bardin T (2003) Estrogens, cartilage, and osteoarthritis. Joint Bone Spine 70:257-262

18. Sniekers YH, Weinans H, Van Osch GJ et al (2010) Oestrogen is important for maintenance of cartilage and subchondral bone in a murine model of knee osteoarthritis. Arthritis Res Ther 12:R182. doi:10.1186/ar3148

19. Cho J, Park W, Lee S et al (2004) Ginsenoside-Rb1 from Panax ginseng C.A. Meyer activates estrogen receptor-alpha and -beta, independent of ligand binding. J Clin Endocrinol Metab 89:3510-3515 